\title{
Evaluation of atorvastatin efficacy and toxicity on spermatozoa, accessory glands and gonadal hormones of healthy men: a pilot prospective clinical trial
}

Hanae Pons-Rejraji ${ }^{1,2 *}$, Florence Brugnon ${ }^{1,2}$, Benoit Sion ${ }^{3}$, Salwan Maqdasy ${ }^{2,4}$, Gerald Gouby ${ }^{5}$, Bruno Pereira ${ }^{6}$, Geoffroy Marceau ${ }^{2,7}$, Anne-Sophie Gremeau', Joel Drevet ${ }^{3,2}$, Genevieve Grizard ${ }^{1}$, Laurent Janny ${ }^{1,2}$ and Igor Tauveron ${ }^{2,4}$

\begin{abstract}
Background: Recommendations for cardiovascular disease prevention advocate lowering both cholesterol and low-density lipoprotein cholesterol systemic levels, notably by statin intake. However, statins are the subject of questions concerning their impact on male fertility. This study aimed to evaluate, by a prospective pilot assay, the efficacy and the toxicity of a decrease of cholesterol blood levels, induced by atorvastatin on semen quality and sexual hormone levels of healthy, normocholesterolaemic and normozoospermic men.
\end{abstract}

Methods: Atorvastatin (10 mg daily) was administrated orally during 5 months to 17 men with normal plasma lipid and standard semen parameters. Spermatozoa parameters, accessory gland markers, semen lipid levels and blood levels of gonadal hormones were assayed before statin intake, during the treatment, and 3 months after its withdrawal.

Results: Atorvastatin treatment significantly decreased circulating low-density lipoprotein cholesterol (LDL-C) and total cholesterol concentrations by $42 \%$ and $24 \%(p<0.0001)$ respectively, and reached the efficacy objective of the protocol. During atorvastatin therapy and/or 3 months after its withdrawal numerous semen parameters were significantly modified, such as total number of spermatozoa $(-31 \%, p<0.05)$, vitality $(-9.5 \%, p<0.05)$, total motility $(+7.5 \%, p<0.05)$, morphology (head, neck and midpiece abnormalities, $p<0.05)$, and the kinetics of acrosome reaction $(p<0.05)$. Seminal concentrations of acid phosphatases $(p<0.01)$, $a$-glucosidase $(p<0.05)$ and L-carnitine $(p<0.05)$ were also decreased during the therapy, indicating an alteration of prostatic and epididymal functions. Moreover, we measured at least one altered semen parameter in $35 \%$ of the subjects during atorvastatin treatment, and in $65 \%$ of the subjects after withdrawal, which led us to consider that atorvastatin is unsafe in the context of our study.

Conclusions: Our results show for the first time that atorvastatin significantly affects the sperm parameters and the seminal fluid composition of healthy men.

Trial registration: ClinicalTrials.gov: NCT02094313.

Keywords: Atorvastatin, Human Spermatozoa, Seminal fluid, Cholesterol, Gonadotropins, Testosterone, Normocholesterolemic, Normozoospermic, Healthy men

\footnotetext{
* Correspondence: hpons-rejraji@chu-clermontferrand.fr

${ }^{1} \mathrm{CHU}$ Clermont Ferrand, Laboratoire de BDR: AMP-CECOS, F-63003

Clermont-Ferrand, France

${ }^{2}$ GReD, UMR CNRS 6293 INSERM U1103, Clermont Université, 63000

Clermont-Ferrand, France

Full list of author information is available at the end of the article
}

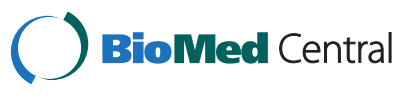

(c) 2014 Pons-Rejraji et al.; licensee BioMed Central Ltd. This is an Open Access article distributed under the terms of the Creative Commons Attribution License (http://creativecommons.org/licenses/by/4.0), which permits unrestricted use, distribution, and reproduction in any medium, provided the original work is properly credited. The Creative Commons Public Domain Dedication waiver (http://creativecommons.org/publicdomain/zero/1.0/) applies to the data made available in this article, unless otherwise stated. 


\section{Background}

In the current context of prevention of cardiovascular risks, a decrease of total cholesterol and low-density lipoprotein cholesterol (LDL-C) plasma levels is an important goal for public health $[1,2]$. Statins are first-choice cholesterol lowering agents $[1,3,4]$. Meta-analysis of data from randomized controlled trials have demonstrated the higher efficiency of statins on the incidence of cardiovascular morbidity and mortality rates compared with other commonly used lipid-modulating therapies [5]. Atorvastatin, the most commonly used statin, is a synthetic, selective and competitive inhibitor of 3-hydroxy-3-methyl-glutarylcoenzyme A (HMG Co-A) reductase. At the molecular level, statins inhibit cholesterol [6] as well as dolichol and coenzyme Q10 [7,8]. Decreased coenzyme Q10 concentration decreases sperm motility, number of spermatozoa, vitality and increases sperm pathology $[8,9]$.

Sterols are essential in male reproductive physiology, notably for steroidogenesis, spermatogenesis and fertilization [10-12]. During spermatogenesis and epididymal maturation, spermatozoa must undergo a major remodeling of their membrane lipid composition and distribution to acquire progressive motility, final morphology and ability to achieve capacitation and acrosome reaction in the female genital tract [13]. Cholesterol efflux from the plasma membrane is a precursor event of capacitation [14-16], leading to the activation of specific intracellular signal transduction pathways [17-19]. Only capacitated spermatozoa are able to undergo an acrosomal reaction in contact with the zona pellucida before fertilizing the oocyte [20].

Since lipid metabolism disorders are associated with impaired fertility [21] or altered sperm parameters [22], in theory statins could permit improvement in sperm parameters in a context of dyslipidemia. However, concern has always existed that statins might impair testosterone production [23] and potentially affect testicular sperm production and/or quality. In fact, in the scientific and medical literature, the effects of statin therapy on steroid levels and sperm parameters in hypercholesterolaemic men are very heterogeneous, depending on dosage, population and comorbidity context [23-34]. Furthermore, for the past 30 years, studies concerning statins have rarely been exhaustive regarding male fertility, focusing more on steroidogenesis impact than on semen quality. Recently, concerns have been raised about the effect of atorvastatin intake on sperm quality [35]. The most commonly used statin, atorvastatin has never been investigated regarding its influence on male fertility, notably on semen quality.

This study is a prospective pilot assay that evaluates the efficacy and the toxicity of a decrease of cholesterol blood levels induced by atorvastatin on the fertility of healthy men without confounding factors. For the first time the effects of atorvastatin were analyzed on human sperm parameters, accessory gland secretions, semen lipid composition and testosterone and gonadotropins systemic concentrations in normocholesterolaemic and normozoospermic subjects.

\section{Methods}

\section{Ethics statement}

Volunteers were recruited in accordance with the 1975 Helsinki declaration on human experimentation, under a protocol approved for research by a Regional Ethical Committee and the French Agency for the Safety of Health Products (AFSSAPS) and was registered in Clinical Trials Register with the identifier number: NCT 02094313. Written informed consent was obtained from subjects before inclusion in the study.

\section{Trial design and subjects}

The main objective of this pilot study was to estimate the toxicity and the efficacy of atorvastatin on fertility of normocholesterolaemic and normozoospermic men by analyzing its effects on sperm parameters. The secondary objective was to assess the evolution of gonadotropins and total testosterone plasma levels, lipid composition of sperm cells and seminal fluid, spermatozoa capacitation ability and accessory glands markers.

Inclusion criteria were healthy men, 18 to 65 years old, with normal conventional semen parameters and negative semen culture according to the 1999 WHO standards [36] and to David's criteria for morphology [37], with normal blood lipid profile (total cholesterol $<2.50 \mathrm{~g} / \mathrm{L}$, triglycerides $<1.70 \mathrm{~g} / \mathrm{L}, \mathrm{HDL}-\mathrm{C}>0.35 \mathrm{~g} / \mathrm{L}$ and $\mathrm{LDL}-\mathrm{C}<2.2 \mathrm{~g} / \mathrm{L}$ ) and without known disease or ongoing treatment. Noninclusion criteria were subjects having a surgical or medical history that might contra-indicate the study, liver disease, prolonged elevation of serum transaminases, lipid parameters not matching with the inclusion criteria, abnormal semen parameters, positive semen culture, cryptorchidism, varicocele, receiving lipid-lowering therapy, or lastly, subjects participating in another clinical study or another experiment over a shorter period than the period of exclusion.

Considering this protocol as a pilot study to evaluate toxicity and efficacy, sample size estimation was fixed according to a one-/multi-stage Fleming design. This design with one group and multi-stages (between 1 and 5) can be seen as filtering steps leading to the "go/no go" decision type. They are among those most used in phase II trials in oncology but remain far more rarely implemented in other areas [38]. With type I error $\alpha$ and statistical power (1- $\beta$ ) values of $5 \%$ and $90 \%$ respectively, 17 subjects were necessary to reject the hypotheses of minimal $(\mathrm{p}=0.85)$ and maximal $(\mathrm{p}=0.95)$ acceptable nontoxicity. If one subject or more presented toxicity, the treatment was considered unsafe. 
The safety/toxicity was evaluated by measuring the effects of atorvastatin on sperm parameters according to the 1999 WHO standards [36] (ejaculate volume $<2 \mathrm{ml}$, sperm count $<20$ millions $/ \mathrm{ml}$, total motility $<50 \%$, progressive motility $<30 \%$ ), to David's criteria for morphology [37] (typical forms $<20 \%$ ) and to BIOFORMA guidelines [39] for accessory gland markers (fructose $\geq 20 \mu \mathrm{mol}$ per ejaculate, citric acid $\geq 60 \mu \mathrm{mol}$ per ejaculate, acid phosphatases $\geq 1234$ UI per ejaculate, neutral alpha 1,4 glucosidase $\geq 59 \mathrm{mU}$ per ejaculate, L-carnitine $\geq 390 \mathrm{nmol}$ per ejaculate).

The efficacy was estimated by measuring the lipid lowering action of atorvastatin with expected final levels $<1.5 \mathrm{~g} / \mathrm{L}$ and $<1 \mathrm{~g} / \mathrm{L}$ for total cholesterol and LDL-cholesterol respectively, or decreases by 20 and $40 \%$ of initials levels of total cholesterol blood and LDL-cholesterol, respectively. To measure the evolution of these parameters 17 subjects were necessary to show the efficacy with a minimal paired difference to be detected of 0.5 , with expected standarddeviation of difference of 0.5 , correlation coefficient of 0.5 , and $\alpha$ value of $5 \%$ (two-sided) for a power greater than $90 \%(1-\beta=97 \%)$.

Thirty-nine subjects were assessed for eligibility (Flow Diagram is presented in Additional file 1: Figure S1). During the screening visit (visit 0 ), routine laboratory biochemical tests were carried out, an electrocardiogram was performed, blood pressure, weight and height were measured; physical examination including testis evaluation and semen parameters were analyzed in the Biology of Reproduction Laboratory of the University Hospital of Clermont-Ferrand according to the 1999 WHO standards [36]. Finally, 17 subjects (mean age $24.4 \pm 0.9$ years) with normal lipid semen parameters were included. The subjects took atorvastatin orally $(10 \mathrm{mg} /$ day $(\mathrm{d})$, Tahor@, Pfizer Laboratory) during 5 months allowing the study of atorvastatin effects on human spermatogenesis and epididymal maturation (one cycle requiring approximately 3 months and maximal efficacy of atorvastatin reached within 4 weeks). Blood and semen parameters were measured before (visit 1), during the 5 months of atorvastatin treatment (visit 3), and 3 months after the end of treatment (visit 4), to perform measurements during different cycles of spermatogenesis on a same subject. Biochemical clinical and semen measurements made before treatment were considered as "control baseline measures". After two months of treatment, a consultation (visit 2) took place to ensure good tolerance of treatment and to control treatment efficiency.

\section{Chemicals}

All chemicals were purchased from Sigma-Aldrich (St Quentin Fallavier, France), unless otherwise indicated.

\section{Biochemical analyses on blood}

Blood was kept on ice in heparin-coated tubes and then centrifuged $15 \mathrm{~min}$ at $1500 \mathrm{~g}$ at $4^{\circ} \mathrm{C}$. Assays were performed on an automated clinical chemistry analyzer (Hitachi Modular; Roche Diagnostics, Meylan, France) based on enzymatic colorimetric (triglycerides, total cholesterol, HDL-C, LDL-C) or electrochemiluminescence assays (total testosterone, FSH, LH) according to the manufacturer's instructions.

\section{Semen parameter measurements}

The ejaculates were collected by masturbation after 3 to 5 days of abstinence. Immediately after liquefaction semen parameters were evaluated according to the WHO guidelines, 1999 [36]. Sperm morphology was studied according to David's criteria with the evaluation of Multiple Anomalies Index (MAI) [37]. Sperm motion analysis was realized with a Hamilton-Thorn Sperm Analyzer (HTM Ceros model 12, Hamilton-Thorn Biosciences, Beverly, MA, USA) as previously described [40]. Seminal levels of fructose (seminal vesicle marker), acid phosphatases and citric acid (prostate markers), and $\alpha$-glucosidase and L-carnitine (epididymal markers) were measured by colorimetric assays as described in the WHO guidelines [36], BIOFORMA guidelines [39] and in a previous work [41].

For semen lipid determination, samples were centrifuged at $500 \mathrm{~g}$ for $5 \mathrm{~min}$. The resulting pellet containing the sperm cells was washed twice in Phosphate-buffered Saline (PBS) by centrifugation (500 g, $5 \mathrm{~min}$ ). The supernatant corresponding to seminal fluid was centrifuged $\left(15 \mathrm{~min}, 10,000 \mathrm{~g}, 4^{\circ} \mathrm{C}\right)$ to remove cell debris. Lipids present in spermatozoa and in seminal fluid were extracted following a modified Folch procedure [42]. The phospholipids and sterols were separated by high performance thin layer chromatography (HPTLC) using a sequential development system as described in a prior study [43].

Capacitation was estimated by measuring two signaling pathway markers. The first marker, is the early cholesterol redistribution in sperm membranes [44,45]. The second involves the phosphorylation of tyrosine residues (P-Tyr) of terminal protein markers P80 and P110 of cAMP - protein kinase A (PKA) signal pathway. Cholesterol redistribution in sperm membranes was estimated by epifluorescence microscopy $(\times 400)$ using filipin, as indicated in prior studies $[44,45]$. Sperm cells with a marked fluorescence in the acrosome region (filipin positive spermatozoa) are not capacitated, while capacitated sperm cells show no fluorescence in the head (filipin negative spermatozoa). For P-Tyr and acrosome integrity assays, spermatozoa were selected using a twostep discontinuous Percoll - HEPES-buffered saline gradient $80-40 \%$ (30 $\mathrm{min}, 1000 \mathrm{~g}$ ). The $80 \%$-fraction was washed once by centrifugation (500 g, $5 \mathrm{~min}$ ) in modified Biggers-Whitten-Whittingham medium supplemented with $3 \mathrm{mg} / \mathrm{ml} \mathrm{BSA}$ and was then incubated in capacitating conditions $\left(37^{\circ} \mathrm{C}, 5 \% \mathrm{CO}_{2}\right)$. P-Tyr and 
acrosome integrity were measured after $5 \mathrm{~min}$ and $3 \mathrm{~h}$ of incubation. P-Tyr of P80 and P110 proteins, was monitored by western-blot using a monoclonal anti-phosphotyrosine antibody (clone 4G10; Upstate Biotechnology Inc, Lake Placid, NY) and a mouse monoclonal anti $\alpha$-tubulin antibody as indicated in a prior study [46]. The phosphotyrosine signal was normalized to the tubulin signal (Figure $1 \mathrm{~B}$ and $\mathrm{C}$ ). The ratios were then related to those obtained before incubation. Acrosome integrity was estimated after spermatozoa fixation, permeabilization in $98 \%$ methanol (30 $\mathrm{min},-20^{\circ} \mathrm{C}$ ), and labeling with a freshly prepared solution of Pisum sativum agglutinin conjugated to fluorescein isothiocyanate (PSA-FITC, $60 \mu \mathrm{g} / \mathrm{ml}$ final) in PBS. Sperm cells were observed blindly using epifluorescence microscopy $(\times 400)$. Sperm cells with an intact acrosome membrane show a marked fluorescence in the acrosome region (A pattern, Figure 1D), while those having lost their acrosome membrane are devoid of fluorescence or display a marked fluorescence along the equatorial segment (AR pattern, Figure 1D).

\section{Statistics}

Statistical analyses were performed with Prism 6 (GraphPad Software) using parametric paired tests. The different parameters measured during and 3 months after the end of atorvastatin treatment were compared with initial values (control baseline values), by one-way paired ANOVA with Holm-Sidak multiple comparison post-test when the distribution was normal; if not we applied a nonparametric post-test (Dunn's Multiple Comparison Test). For each comparison, the corresponding effectiveness was checked to verify the robustness of the analysis.

\section{Results}

Baseline clinical and biochemical characteristics of studied subjects are summarized in Tables 1 and 2. All the subjects were healthy men between 20 and 38 years old (Table 1), with normal renal, hepatic and cardiac functions, body mass index (Table 1) and serum lipid parameters (Table 2) and without known pathology or ongoing treatment. During the 5-month atorvastatin intake period, 15 subjects had a total cholesterol serum level $<1.5 \mathrm{~g} / \mathrm{L}$ and 16 subjects had a LDL-cholesterol level $<1 \mathrm{~g} / \mathrm{L}$, achieving the protocol efficacy goal. We measured a significant decrease of both total cholesterol $(-24 \%, \mathrm{p}<0.0001$, Table 2$)$ and LDL-C (- 42\%, p $<0.0001$, Table 2) blood mean levels. Three months after atorvastatin withdrawal, values of total cholesterol and LDL-C were comparable to those observed before treatment. The serum levels of triglycerides, HDL-C, testosterone, FSH and LH were not affected by atorvastatin (Table 2), nor were the measured blood, hepatic, renal and cardiac markers (data not shown).

The reduction of cholesterol level in serum did not significantly affect semen cholesterol and phospholipid levels, whether in spermatozoon or in seminal fluid (Table 3). However, we noted that the cholesterol/phospholipids ratio tended to decrease both in sperm cells and in seminal fluid during the treatment.

Mean values of semen parameters were significantly altered by atorvastatin intake (Table 3 ). Total sperm number $(-31 \%)$ and vitality $(-9.5 \%)$ were significantly reduced, notably after treatment withdrawal $(\mathrm{p}<0.05)$. The teratozoospermia Multiple Anomalies Index (MAI) and the number of head, neck and midpiece abnormalities were significantly increased $(\mathrm{p}<0.05)$, even if the proportion of morphologically abnormal spermatozoa was not globally modified. Conversely, total motility was slightly but significantly improved during treatment $(65.5 \pm 2.2 \%$ during vs. $60.9 \pm 1.8 \%$ before, $\mathrm{p}<0.05$ ), with no effect either on progressive motility or on sperm motion parameters. When the effects were analyzed per subject, 2 out of 17 men were necro- and asthenozoospermic according to the WHO 1999 standards, notably after withdrawal of treatment (Figure 2A and B), exceeding the safety limits of the study.

Markers of the accessory sex glands were also perturbed. The amount of prostatic acid phosphatases was significantly reduced 3 months after atorvastatin withdrawal ( $\mathrm{p}<0.01$ vs. control value, Figure 3B). Similarly, the levels of epididymal neutral $\alpha$-glucosidase and L-carnitine were significantly decreased $(\mathrm{p}<0.01$ and $\mathrm{p}<0.05$ for $\alpha$-glucosidase and L-carnitine, respectively, Figure $3 \mathrm{C}$ ). Regarding individual impact, one patient presented an abnormal value for neutral $\alpha$-glucosidase $(6 \%$ value, $<59 \mathrm{mU}$, Figure 3D) before the beginning of treatment according to BIOFORMA standards. During the treatment 35\% (6 subjects) showed altered activity of neutral $\alpha$-glucosidase with a mean value of $40.0 \pm 7.6 \mathrm{mU}$. Three months after the end of therapy, more than half of the subjects presented an abnormal value of neutral $\alpha$-glucosidase $(53 \%, 9$ subjects Figure 3D) with an activity mean of $43.8 \pm 7.8 \mathrm{mU}$. Atorvastatin effects on neutral $\alpha$-glucosidase again exceeded the safety limits fixed by the study.

To further evaluate the fertilizing ability of spermatozoa, capacitation and acrosome reaction were measured in capacitating conditions. Spermatozoa capacitation was evaluated by measuring early markers such as cholesterol depletion from plasma membrane and terminal markers of signaling pathways corresponding to the PTyr levels of proteins P80 and P110. Atorvastatin treatment had no effect on the proportion of filipin negative spermatozoa (Figure 1A) nor on the P-Tyr level of the two protein markers of capacitation P110 and P80 (Figure $1 \mathrm{~B}$ and $\mathrm{C}$ ). However, it was observed that the level of P-Tyr tended to increase during treatment and 3 months after atorvastatin withdrawal. The proportion of spontaneous acrosome-reacted (AR, Figure 1D) spermatozoa tended to be reduced by the cholesterol- 
A

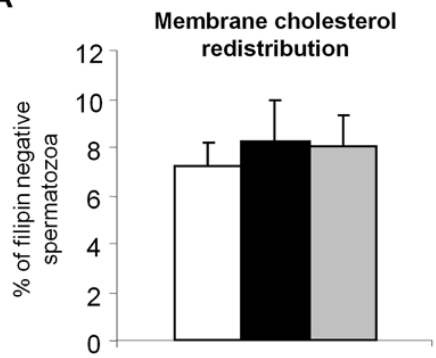

B

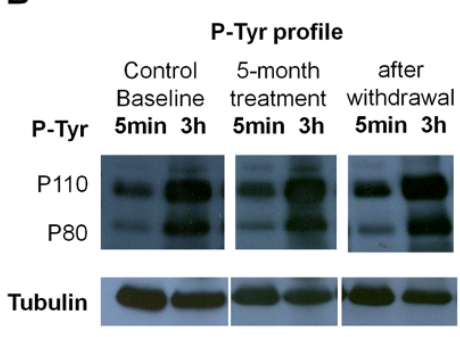

D

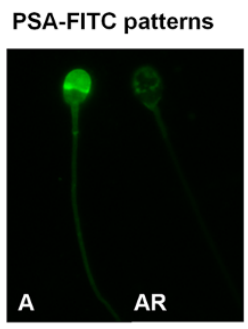

C

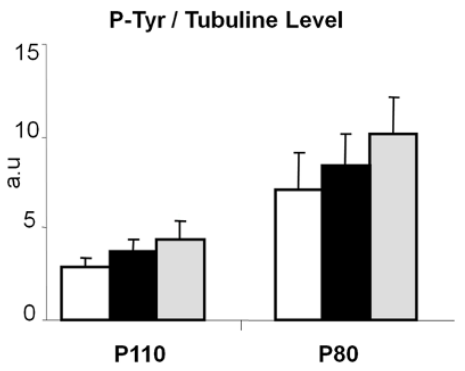

E

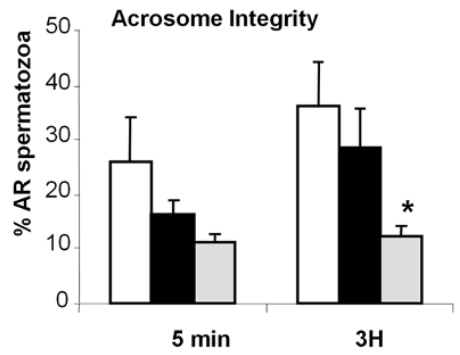

Figure 1 Atorvastatin effects on membrane cholesterol distribution, P-Tyr and acrosome reaction in spermatozoa. Membrane cholesterol distribution, P-Tyr and acrosome integrity were analysed in spermatozoa obtained from 17 normocholesterolaemic men before, during and 3 months after the end of treatment as described in Methods. P-Tyr patterns were assessed before $(t=0 \mathrm{~h})$ and after ( $\mathrm{t}=3 \mathrm{~h}$ ) incubating spermatozoa in capacitating conditionsd and visualized by western blotting using a monoclonal anti-phosphotyrosine antibody. To calibrate the signal for the amount of sperm protein, the same membranes were reprobed using a monoclonal anti-alpha-tubulin antibody. Acrosome integrity was assessed before ( $5 \mathrm{~min}$ ) and after $3 \mathrm{~h}$ of incubation in capacitating conditions ( $3 \mathrm{~h}$ ), by epifluorescence microscopy ( $\mathrm{x} 400$ ) using PSA-FITC as a probe. A represents mean \pm SEM of the percentage of sperm cells showing a redistribution of cholesterol with filipin labelling absent in the sperm head. Cholesterol distribution was estimated by epifluorescence microscopy (x400) using filipin as a probe. B represents typical patterns of protein tyrosine phosphorylation (P-Tyr) and a-tubulin in human spermatozoa. $\mathbf{C}$ represents P-Tyr signal normalized to the tubulin signal and the ratios were related to the basal signal obtained before incubation. Data are represented as mean \pm SEM in arbitrary units (a.u.). D represents a fluorescence micrograph showing a sperm cell with an intact acrosome membrane (A pattern: marked fluorescence in the acrosome region) and a sperm cell without an acrosome membrane (AR pattern: no fluorescence or marked fluorescence along the equatorial segment). $\mathbf{E}$ represents mean \pm SEM of the percentage of AR spermatozoa. *indicates values significantly different from those measured before atorvastatin intake with $p<0.05$.

lowering therapy $(16.1 \pm 3.0 \%$ during $v s .26 .1 \pm 7.8 \%$ before treatment, $5 \mathrm{~min}$, Figure 1E) and after $3 \mathrm{~h}$ of incubation under capacitating conditions $(28.3 \pm 7.4 \%$ vs. $36.1 \pm 8.5 \%$ before atorvastatin intake, Figure $1 \mathrm{E})$. This trend was also observed 3 months after the end of the therapy and became significant for the AR proportion obtained after $3 \mathrm{~h}$ of incubation under capacitating conditions $(12.3 \pm 2.0 \%, \mathrm{p}<0.05$ in comparison with values before atorvastatin treatment).

\section{Discussion}

This is the first study evaluating atorvastatin effects on semen quality and testicular steroidogenesis regulation in normocholesterolaemic, young and healthy men. This work is a prospective non-controlled pilot assay evaluating atorvastatin efficacy and toxicity on human semen parameters. A 5-month atorvastatin intake $(10 \mathrm{mg} / \mathrm{d})$ induced a significant decrease in serum levels of total cholesterol and LDL-C achieving the efficacy goal of the 


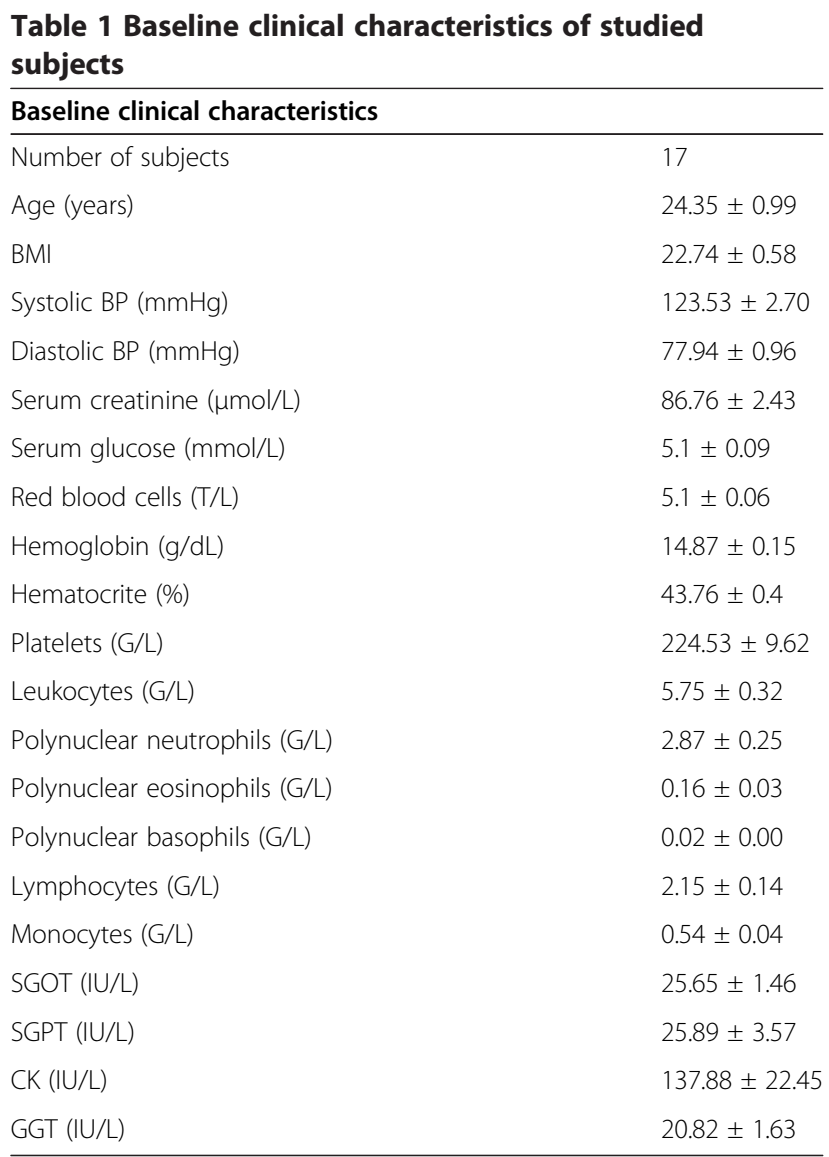

Data are presented as the mean \pm SEM. BMI: Body Mass Index; BP: blood pressure; SGOT: serum glutamic oxaloacetic transaminase; SGPT: serum glutamic-pyruvic transaminase, CK: Creatine kinase, GGT: Gamma-glutamyl transpeptidase.

Table 2 Effects of atorvastatin on blood concentrations of lipids and hormones

\begin{tabular}{|c|c|c|c|}
\hline & $\begin{array}{l}\text { Control } \\
\text { baseline }\end{array}$ & $\begin{array}{l}\text { 5-month } \\
\text { treatment }\end{array}$ & $\begin{array}{l}3 \text { months after } \\
\text { withdrawal }\end{array}$ \\
\hline \multicolumn{4}{|l|}{ Serum levels of lipids } \\
\hline Total cholesterol (g/L) & $1.67 \pm 0.08$ & $1.27 \pm 0.07^{* * *}$ & $1.71 \pm 0.08$ \\
\hline Triglycerides (g/L) & $0.83 \pm 0.06$ & $0.73 \pm 0.11$ & $0.93 \pm 0.14$ \\
\hline $\mathrm{HDL}-\mathrm{C}(\mathrm{g} / \mathrm{L})$ & $0.53 \pm 0.03$ & $0.52 \pm 0.03$ & $0.51 \pm 0.03$ \\
\hline $\mathrm{LDL}-\mathrm{C}(\mathrm{g} / \mathrm{L})$ & $0.98 \pm 0.07$ & $0.57 \pm 0.05^{* * *}$ & $0.98 \pm 0.07$ \\
\hline \multicolumn{4}{|l|}{ Serum levels of hormones } \\
\hline $\mathrm{FSH}(\mathrm{UI} / \mathrm{L})$ & $2.85 \pm 0.30$ & $2.87 \pm 0.33$ & $2.89 \pm 0.30$ \\
\hline LH (UI/L) & $4.47 \pm 0.54$ & $5.00 \pm 0.37$ & $4.57 \pm 0.35$ \\
\hline Total testosterone (nmol/L) & $22.71 \pm 1.56$ & $24.04 \pm 1.99$ & $22.81 \pm 1.71$ \\
\hline \multicolumn{4}{|c|}{$\begin{array}{l}\text { Data are presented as mean } \pm \text { SEM. Seventeen normocholesterolaemic men } \\
\text { received } 10 \mathrm{mg} / \mathrm{d} \text { atorvastatin during } 5 \text { months as described in Methods. The } \\
\text { serum levels of total cholesterol, triglycerides, HDL-C, LDL-C, FSH, LH and total } \\
\text { testosterone were measured before, during and } 3 \text { months after the end of } \\
\text { treatment. }{ }^{* * *} \text { indicates values significantly different from those obtained } \\
\text { before treatment with } \mathrm{p}<0.001 \text {. }\end{array}$} \\
\hline
\end{tabular}

protocol. Atorvastatin treatment affected semen parameters significantly. It also decreased the total number of spermatozoa in ejaculate and sperm vitality, increased morphological abnormalities and total motility, and altered acrosome reaction kinetics. Seminal concentrations of acid phosphatases, $\alpha$-glucosidase and L-carnitine were also decreased. All these results hint at deleterious effects of atorvastatin on testicular, prostatic and epididymal functions.

At the end of the study, 9 subjects (53\%) had an alteration of at least one semen marker; two men were necro-asthenozoospermic and had a low value of neutral $\alpha$-glucosidase. We had specified that if one subject or more presented toxicity on sperm or accessory gland markers, the treatment was considered unsafe. The results obtained led to the decision to stop the protocol and to conclude in the efficacy but also the toxicity of atorvastatin for semen parameters. To further evaluate the fertilizing ability of spermatozoa, capacitation and acrosome reaction were measured in capacitating conditions. To our knowledge, fertilizing ability has never been studied in the context of a cholesterol-lowering therapy in humans. Atorvastatin had no significant effect on early (cholesterol depletion from plasma membrane) or terminal markers (P-Tyr levels of proteins P80 and P110) $[19,47]$ of capacitation. Nevertheless, the proportion of acrosome-reacted spermatozoa was significantly decreased by atorvastatin intake.

Our study showed that atorvastatin therapy does not alter cholesterol and phospholipid composition of human spermatozoa and seminal fluid. This is consistent with our previous study showing that normo- and hypercholesterolaemic men had similar amounts of cholesterol and phospholipids in semen [41]. The same observations were made in the rabbit [48-50], with, however, a modification of sterol distribution in acrosome and plasma membranes, and significant alterations of sperm parameters. In our study, we did not observe any significant modification of cholesterol distribution in the human sperm head as shown by filipin fluorescence, even if acrosome reaction kinetic was slightly altered. These discrepancies could be explained by differences in cholesterol regulation between the different models. Nevertheless, we can exclude yhe postalte that atorvastatin could affect other sterols in the human sperm membrane.

Similarly, modifications of systemic cholesterol metabolism do not significantly modify cholesterol and phospholipid levels in semen. These data could explain the absence of effects of atorvastatin on systemic levels of total testosterone and gonadotropins. Nevertheless, sperm production and quality were decreased and prostatic and epididymal markers were altered. Such data indicate clearly that atorvastatin therapy affects testicular, epididymal and prostatic functions. Testis, epididymis 
Table 3 Effects of atorvastatin on human semen parameters and lipids composition

\begin{tabular}{|c|c|c|c|}
\hline & $\begin{array}{l}\text { Control } \\
\text { baseline }\end{array}$ & $\begin{array}{l}\text { 5-month } \\
\text { treatment }\end{array}$ & $\begin{array}{l}3 \text { months after } \\
\text { withdrawal }\end{array}$ \\
\hline \multicolumn{4}{|c|}{ Conventional semen parameters } \\
\hline Semen volume (ml) & $3.9 \pm 0.4$ & $4.0 \pm 0.6$ & $3.5 \pm 0.4$ \\
\hline Semen pH & $8.0 \pm 0.1$ & $7.9 \pm 0.1$ & $8.1 \pm 0.2$ \\
\hline $\begin{array}{l}\text { Sperm concentration } \\
\left(10^{6} \mathrm{spz} / \mathrm{ml}\right)\end{array}$ & $146.1 \pm 17.8$ & $119.1 \pm 15.6$ & $109.9 \pm 14.8$ \\
\hline $\begin{array}{l}\text { Sperm number } \\
\left(10^{6} \mathrm{spz} / \text { ejaculate }\right)\end{array}$ & $540.5 \pm 83.3$ & $449.1 \pm 75.6$ & $375.0 \pm 60.5^{*}$ \\
\hline Vitality (\%) & $85.2 \pm 1.5$ & $78.8 \pm 1.7^{* *}$ & $77.1 \pm 2.7^{*}$ \\
\hline Total motility (\%) & $60.9 \pm 1.8$ & $65.5 \pm 2.2^{*}$ & $62.7 \pm 2.5$ \\
\hline Progressive motility (\%) & $57.9 \pm 1.8$ & $58.6 \pm 2.2$ & $58.0 \pm 2.8$ \\
\hline VSL $(\mu \mathrm{m} / \mathrm{s})$ & $50.4 \pm 2.9$ & $47.5 \pm 1.5$ & $50.6 \pm 2.5$ \\
\hline VCL $(\mu \mathrm{m} / \mathrm{s})$ & $84.6 \pm 2.5$ & $80.8 \pm 2.3$ & $87.1 \pm 3.2$ \\
\hline Linearity (\%) & $61.1 \pm 2.2$ & $58.8 \pm 1.4$ & $57.9 \pm 2,0$ \\
\hline $\mathrm{ALH}(\mu \mathrm{m})$ & $3.7 \pm 0.2$ & $3.6 \pm 0.1$ & $3.8 \pm 0.2$ \\
\hline Sperm abnormalities (\%) & $64.5 \pm 2.6$ & $63.5 \pm 2.4$ & $66.4 \pm 2.4$ \\
\hline Head abnormalities & $66.1 \pm 4,0$ & $64.8 \pm 3.5$ & $73.5 \pm 4.6^{\ddagger}$ \\
\hline Excess residual cytoplasm & $3.1 \pm 0.6$ & $5.8 \pm 1.3$ & $5.2 \pm 0.9$ \\
\hline $\begin{array}{l}\text { Neck and midpiece } \\
\text { abnormalities }\end{array}$ & $13.3 \pm 1.9$ & $13.0 \pm 2.2$ & $17.7 \pm 1.7^{*}$ \\
\hline Tail abnormalities & $6.6 \pm 1.0$ & $4.7 \pm 0.8$ & $6.9 \pm 1.2$ \\
\hline $\mathrm{MAl}$ & $1.6 \pm 0.18$ & $1.41 \pm 0.03$ & $1.54 \pm 0.05^{\text {fキ }}$ \\
\hline
\end{tabular}

Cholesterol and phospholipid concentrations in Spermatozoa (nmol/10 ${ }^{8}$ )

$\begin{array}{llll}\text { Cholesterol } & 80.94 \pm 6.08 & 95.47 \pm 9.88 & 93.32 \pm 8.09 \\ \text { PE } & 50.46 \pm 6.10 & 61.82 \pm 6.32 & 57.37 \pm 6.91 \\ \text { PC } & 120.55 \pm 17.84 & 158.00 \pm 18.09 & 142.97 \pm 16.83 \\ \text { SM } & 34.48 \pm 4.11 & 42.56 \pm 6.47 & 32.61 \pm 2.42 \\ \text { Cholesterol/(PE + } & 0.46 \pm 0.04 & 0.39 \pm 0.03 & 0.44 \pm 0.05 \\ \text { PC + SM) ratio } & & & \end{array}$

Cholesterol and phospholipid concentrations in Seminal fluid ( $\mu \mathrm{mol} / \mathrm{ml}$ )

\begin{tabular}{llll} 
Cholesterol & $34.38 \pm 2.55$ & $35.24 \pm 3.00$ & $34.48 \pm 3.33$ \\
PE & $5.52 \pm 0.64$ & $6.10 \pm 0.73$ & $7.95 \pm 1.75$ \\
PC & $6.95 \pm 0.78$ & $7.21 \pm 0.95$ & $7.90 \pm 2.09$ \\
SM & $12.58 \pm 1.38$ & $12.71 \pm 1.42$ & $12.07 \pm 1.14$ \\
Cholesterol/(PE + & $1.44 \pm 0.06$ & $1.40 \pm 0.06$ & $1.36 \pm 0.07$ \\
PC + SM) ratio & & & \\
\hline
\end{tabular}

Data are presented as the mean \pm SEM. Seventeen normocholesterolaemic men received $10 \mathrm{mg} / \mathrm{d}$ atorvastatin during 5 months as described in Methods. The semen parameters and cholesterol and phospholipid concentrations were measured before (control baseline values), during and 3 months after the end of treatment.

VSL: straight line velocity; VCL: curvilinear velocity; ALH: amplitude of lateral head displacement; MAl: Multiple Anomalies Index; PE: phosphatidylethanolamine; PC: phosphatidylcholine; SM: sphingomyelin. *and **indicate that the value is significantly different from those obtained before treatment with $p<0.05$ and $\mathrm{p}<0.01$ respectively. ${ }^{\ddagger}$ and ${ }^{\ddagger \neq}$ indicate that the value is significantly different from the value measured during atorvastatin uptake with $p<0.05$ and $p<0.01$ respectively.
[51,52] and prostate [53] are androgen-dependent organs. Epididymal secretion of $\alpha$-glucosidase, specifically, is androgen - dependent [54,55]. Since gonadotropin and testosterone plasma levels were not affected, we can exclude a direct effect of peripheral blood sexual hormones. Furthermore, the main income of testosterone in the epididymis is through the efferent ducts [51,52]. An hypothesis could be that atorvastatin induced a local and minor alteration of testosterone and/or dihydrotestosterone (DHT) homeostasis in the genital tract that does not impact testosterone and gonadotropin systemic levels. Epididymal, testicular or spermatic cord blood measures of androgen levels are difficult to perform in the humans to verify this hypothesis. Maybe the seminal fluid assays of testosterone and DHT would be indicative. Use of animal models could also allow deepening the effect of atorvastatin on male genital tract and notably on testicular steroïdogenesis. This should allow at least a measurement of the intratesticular level of androgens.

We could also consider that atorvastatin might induce local inflammation or oxidative stress with persistent effects on prostatic and epididymal secretion. A recent study has characterized prostatic acid phosphatases regulation in androgen-dependent and -independent manner [56], suggesting that it could be considered that statin effects on the genital tract could be more complex than an androgen-mediated action. Moreover, most of the effects of atorvastatin were observed 3 months after stopping the treatment, despite the return of cholesterol and LDL-C to normal levels. It would have been interesting to follow the subjects for a longer time after atorvastatin withdrawal to determine when the parameters returned to baseline.

This persistent effect could indicate that atorvastatin effects on the genital tract could be also mediated by a messenger or an intermediary that persists after the end of therapy. In 2005, Niederberger raised the question of the adverse effect of atorvastatin on human fertility [35]. One hypothesis to explain this action is that atorvastatin induces a decrease in ubiquinone oxido-reductase (Coenzyme Q10) level. The enzyme represents an important intracellular antioxidant for spermatozoa in the seminal fluid and its concentration in seminal fluid is positively correlated with sperm motility [57,58]. Recently, it was proposed that statins could act by three major intracellular mechanisms implicating insulin signaling transduction pathway, ATP and calcium regulation [8]. Atorvastatin could also affect important downstream products such as Coenzyme Q10, farnesyl pyrophosphate, geranylgeranyl pyrophosphate, and dolichol. A last hypothesis could be that atorvastatin acts via these different products leading to alterations of intracellular signaling pathways in genital tract tissue or sperm cells, associated or not with an oxidative stress. Once again, animal models could be an 

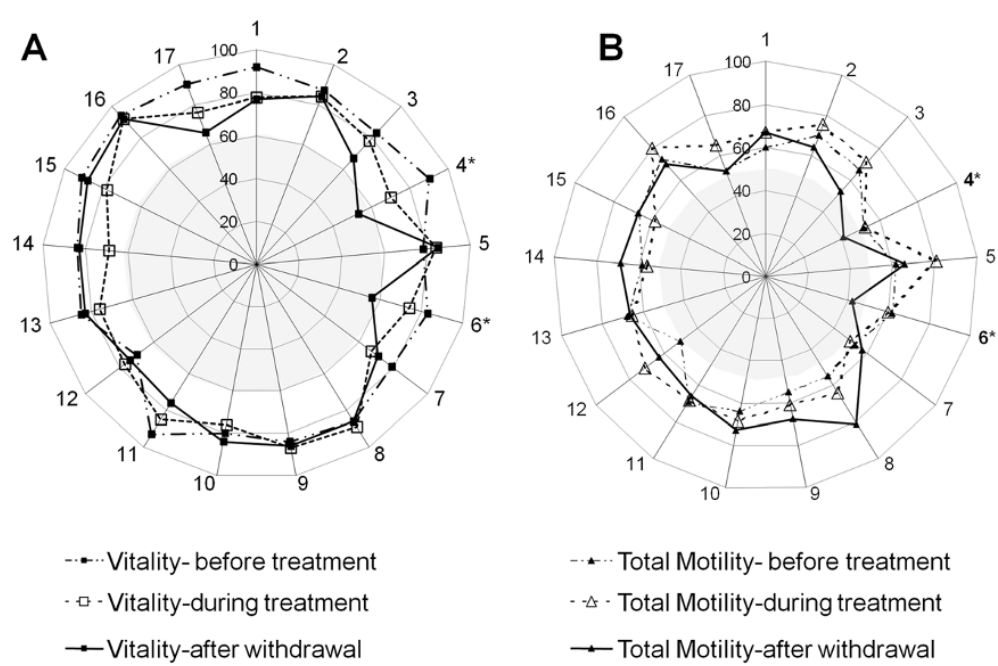

Figure 2 Effects of atorvastatin on human sperm vitality and progressive motility. Percentages of viable (A) and total motile (B) spermatozoa of the seventeen subjects are represented in the spider graphs before (control baseline values), during and 3 months after the end of treatment. *indicates patients having altered sperm parameters according to WHO standards.

interesting perspective to characterize atorvastatin effects on the genital tract.

A major deleterious effect of atorvastatin was observed on secretory gland markers, notably on epididymal markers. Purvis et al., in 1992 ([23,59], Additional file 2: Table S1) measured no effect of simvastatin intake (3.5 months at $40 \mathrm{mg} / \mathrm{d}$ ) on human accessory gland markers. However, it was established that statins can affect the prostate, notably prostate-specific antigen (PSA) serum levels [60,61], and can act within prostate cell membrane on discrete regions known as lipid rafts $[6,62]$. Furthermore it was demonstrated that statins, notably simvastatin, have an effect on the synthesis and secretion of cholesterol by human PC3prostate cancer cells via prostasomes [63,64]. In contrast to acid phosphatases, the seminal levels of citric acid (another prostate marker) and sterols (whose main source is the prostate) remained unchanged. These data suggest that atorvastatin could affect specifically the synthesis and/or the secretion of acid phosphatases, possibly by targeting specific prostatic cells or by a specific signaling pathway. A previous study has demonstrated that the seminal L-carnitine level was significantly increased in men with hypercholesterolemia [41]. The epididymis is the site of sperm maturation and acquisition of linear and progressive motility. We found moderate but significant changes in the morphology and motility of sperm, in accordance with an effect of atorvastatin on the primary functions of the epididymis.

The main objective of this study was to determine specific effects of atorvastatin intake on semen parameters and hormonal regulation of young men in the context of secondary cardiovascular prevention. Previous studies (for details see Additional file 2: Table S1) have shown deleterious effects of simvastatin or pravastatin on human sperm parameters [65-67]. A few others measured no effect of pravastatin or simvastatin intake on sperm quality $[28,59]$. In all these studies, statin effects were of low amplitude and values measured after therapy remained within normal values, indicating no clinical deleterious impact on human sperm quality.

Similarly, some authors reported an association between statin therapy and hypogonadism $[25,27,33,34,60,68]$, while others did not, notably at low or moderate doses (between 10 and $40 \mathrm{mg} / \mathrm{d}$ ) of simvastatin $[29,59,65]$, pravastatin $[28,29,65,66,69,70]$, lovastatin [67] or atorvastatin [30,71]. Since these different statins have different hydrophilic properties, it cannot be excluded that their pharmacokinetic or physicochemical properties have an impact on their effects. Recently, a meta-analysis of placebo randomized controlled trials of statins demonstrated that statin therapy decreased testosterone by 0.66 in middle-aged men with hypercholesterolemia [23]. Nevertheless, this average change is limited, while the range of normal values for testosterone is quite wide. Moreover, male hypogonadism and dyslipidaemia have been associated with different concomitant morbid factors including age, renal disease, type 2 diabetes, obesity, liver cirrhosis, metabolic syndrome or erectile dysfunction [23,30,31,33,68,72-76]. These comorbidity factors could be confounding elements and, at least partially, responsible for the deleterious effects on androgen regulation and sperm quality. In this study, we measured the effects of statins on the fertility of young, healthy and normocholesterolaemic subjects without confounding factors. Only one previous study analyzed the 
A

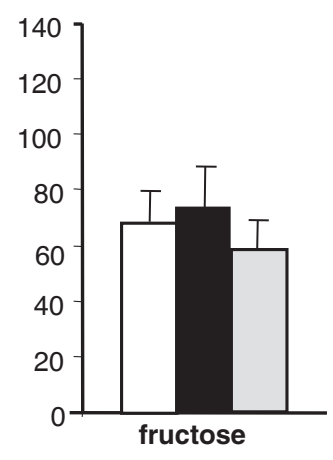

C

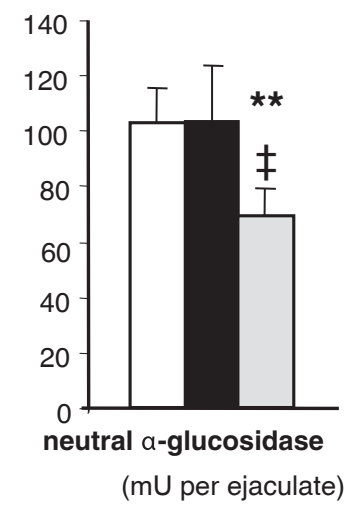

D

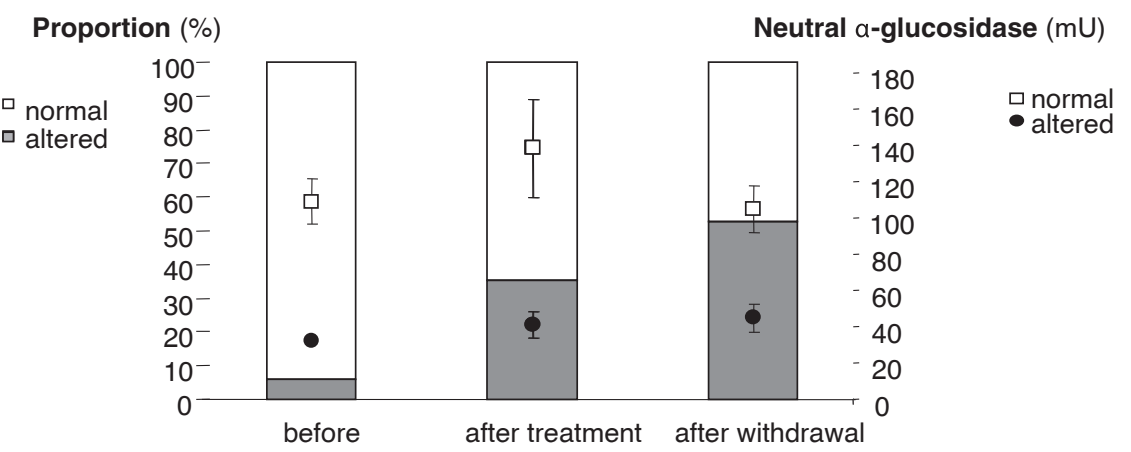

\section{B}
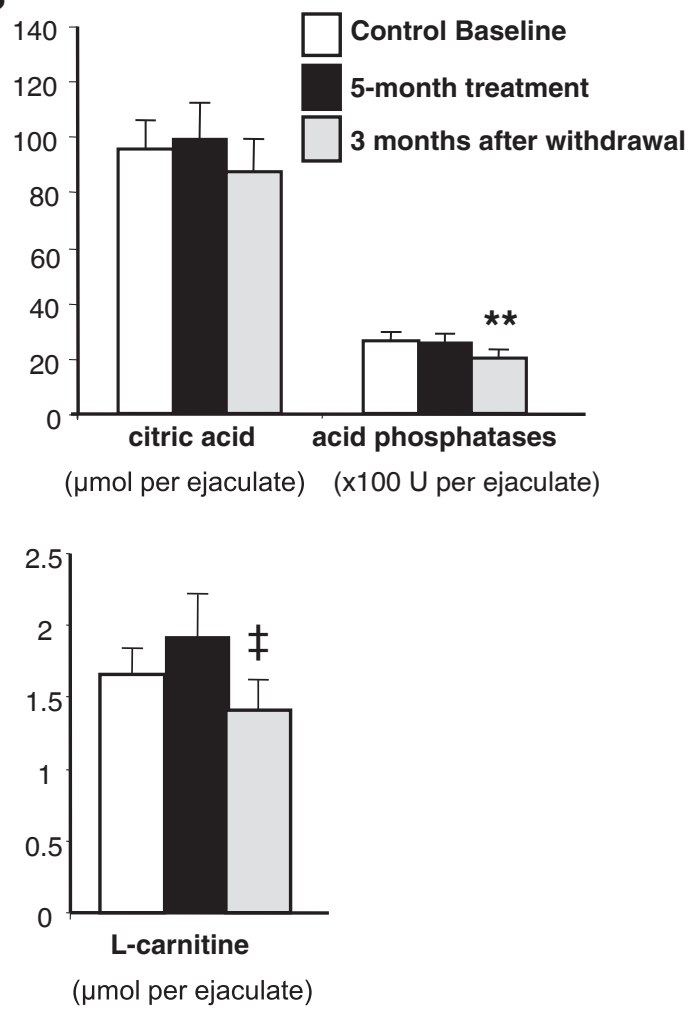

Figure 3 Atorvastatin effects on markers of the accessory sex glands. The seminal levels of fructose (A) (seminal vesicle marker), acid phosphatases and citric acid (B (prostate markers), and alpha-glucosidase and L-carnitine (C and D) (epididymal markers) were measured in 17 normocholesterolaemic men before, during and 3 months after the end of treatment, as described in Methods. In A, B and C, bar represents mean \pm SEM. **indicates values significantly different from those obtained before atorvastatin intake with $p<0.01$ and $\neq$ indicates values significantly different from those measured during atorvastatin treatment with $p<0.05$. In $\mathrm{D}$, bars (white and coloured) and symbols (points and squares) represent mean \pm SEM and percentages respectively of the subjects having normal (white) and altered (coloured) values of neutral a-glucosidase activity before, during and 3 months after the end of treatment.

effects of statins on healthy men, and only steroidogenesis was explored [77].

Our work demonstrates that atorvastatin therapy, at $10 \mathrm{mg}$ daily, had no effect on total testosterone and gonadotropin serum level but affected significantly sperm parameters of young and healthy men and was considered as deleterious in the context of our protocol. Yet, in view of our results in this young population, it may be considered that the effects could be more pronounced among older men specifically if less healthy. For this pilot assay, control baseline values were measured for each subject before the beginning of the atorvastatin treatment, rather than include a placebo-treated group allowing us to limit the high inter-individual variability and to include a relatively small numbers of subjects. A perspective will be to perform a randomized placebo-controlled assay with a 
larger cohort and a longer study time to confirm and deepen atorvastatin effects on men fertility.

\section{Conclusions}

In conclusion, our study shows for the first time that the intake of atorvastatin by healthy and normocholesterolaemic subjects significantly affected their sperm parameters (vitality, number, motility, morphology and acrosome reaction) and changed their seminal fluid composition. These consequences occurred after only 5 months of treatment. Considering the long duration of statin treatment, for which the clinical benefit with respect to cardiovascular diseases is beyond question, potential negative consequences on reproductive function should be taken into account when deciding to initiate such a treatment, notably for young adults.

\section{Additional files}

Additional file 1: Figure S1. Flow diagram. After a screening visit (visit 0 ) allowing inclusion and exclusion of subjects by the measurement of the clinical, blood and semen baseline parameters, serum and semen parameters of subjects were assayed in the laboratory during 4 visits corresponding to the beginning of atorvastatin treatment (10mg daily) (visit 1); a control visit to ensure good tolerance to treatment and its efficiency after 2 months of therapy (visit 2) and the measurement of the effects of a 5-month atorvastatin intake (visit 3) and the residual effects after 3 months of treatment withdrawal (visit 4).

Additional file 2: Table S1. Prospective studies analyzing statin effects on human gonadal steroidogenesis and semen quality. *after 6 months of therapy, ref:: reference, treat:. treatment, normochol.: normocholesterolæmic; hyperchol.: hypercholesteroleamic. Test: testosterone, Num: sperm number, Motil: sperm motility; Morph: sperm morphology; Acc. glands: Accessory glands; Cap: capacitation; AR: Acrosome reaction.

\section{Competing interests}

The authors declare that they have no competing interests.

\section{Authors' contributions}

HPR participated in the design of the study and its coordination, carried out semen assays and drafted the manuscript. FB participated in the design of the study, its coordination, in the inclusion of the patients and helped to draft the manuscript. BS participated in the design of the study, carried out the semen lipid and filipin assays and helped to draft the manuscript. SM carried out the carnitine assay. GG participated in the design of the study and helped to draft the manuscript. BP performed the statistical analysis and helped to draft the manuscript. GM performed blood biochemical analyses. ASG performed the physical examination of the patients, including testis evaluation. JRD helped to draft the manuscript. GG conceived the study and participated in its design and coordination and helped to draft the manuscript. $L$ conceived the study and participated in its design and in the inclusion of the patients, and helped to draft the manuscript. IT conceived the study and participated in its design and coordination and helped to draft the manuscript. All authors read and approved the final manuscript.

\section{Acknowledgements}

This study was supported by a local hospital grant from the Hospital Clinical Research Program of the French Ministry of Health (PHRC L 06 Tauveron), and the DRCl of Clermont-Ferrand university hospital. The authors thank Elizabeth Petit and Dr. Christine Rondanino for revising the English language.

\section{Author details}

${ }^{1} \mathrm{CHU}$ Clermont Ferrand, Laboratoire de BDR: AMP-CECOS, F-63003 Clermont-Ferrand, France. ${ }^{2}$ GReD, UMR CNRS 6293 INSERM U1103, Clermont
Université, 63000 Clermont-Ferrand, France. ${ }^{3}$ Pharmacologie Fondamentale et Clinique de la Douleur, France Inserm, U 1107, Neuro-Dol, Clermont Université, Université d'Auvergne, F-63001 Clermont-Ferrand, France. ${ }^{4} \mathrm{CHU}$ Clermont-Ferrand, Service d'Endocrinologie-Diabétologie, F-63003 Clermont-Ferrand, France. ${ }^{5} \mathrm{CHU}$ de Clermont-Ferrand, Délégation à la Recherche Clinique et à I'Innovation (DRCI), F-63003 Clermont-Ferrand, France. ${ }^{6} \mathrm{CHU}$ Clermont-Ferrand, Biostatistics unit, DRCl, Clermont-Ferrand, France. ${ }^{7} \mathrm{CHU}$ Clermont-Ferrand, Laboratoire de Biochimie, F-63003 Clermont-Ferrand, France.

Received: 1 April 2014 Accepted: 7 July 2014

Published: 12 July 2014

\section{References}

1. Armitage J: The safety of statins in clinical practice. Lancet 2007, 370(9601):1781-1790.

2. Lewington S, Whitlock G, Clarke R, Sherliker P, Emberson J, Halsey J, Qizilbash N, Peto R, Collins R: Blood cholesterol and vascular mortality by age, sex, and blood pressure: a meta-analysis of individual data from 61 prospective studies with 55,000 vascular deaths. Lancet 2007, 370(9602):1829-1839.

3. Baigent C, Blackwell L, Emberson J, Holland LE, Reith C, Bhala N, Peto R, Barnes EH, Keech A, Simes J, Collins R, Cholesterol Treatment Trialists' (CTT) Collaboration: Efficacy and safety of more intensive lowering of LDL cholesterol: a meta-analysis of data from 170,000 participants in 26 randomised trials. Lancet 2010, 376(9753):1670-1681.

4. Ward S, Lloyd Jones M, Pandor A, Holmes M, Ara R, Ryan A, Yeo W, Payne $\mathrm{N}$ : A systematic review and economic evaluation of statins for the prevention of coronary events. Health Technol Assess 2007, 11(14):1-160. iii-iv.

5. Gotto AM Jr, Moon JE: Recent clinical studies of the effects of lipidmodifying therapies. Am J Cardiol 2012, 110(1 Suppl):15A-26A.

6. Solomon KR, Freeman MR: Do the cholesterol-lowering properties of statins affect cancer risk? Trends Endocrinol Metab 2008, 19(4):113-121.

7. Grozdjakova A, Kucharska J, Sykora L, Singh RB: Balneotherapy and coenzyme Q10 in clinical and experimental medicine. Front Biosci (Schol Ed) 2013, 6:29-38.

8. Brault M, Ray J, Gomez YH, Mantzoros CS, Daskalopoulou SS: Statin treatment and new-onset diabetes: a review of proposed mechanisms. Metabolism 2014, 63(6):735-745.

9. Littarru GP, Langsjoen P: Coenzyme Q10 and statins: biochemical and clinical implications. Mitochondrion 2007, 7(Suppl):S168-S174.

10. Travis AJ, Kopf GS: The role of cholesterol efflux in regulating the fertilization potential of mammalian spermatozoa. J Clin Invest 2002, 110(6):731-736.

11. Cross NL: Role of cholesterol in sperm capacitation. Biol Reprod 1998, 59(1):7-11.

12. Brewis IA, Moore HD, Fraser LR, Holt WV, Baldi E, Luconi M, Gadella BM, Ford WC, Harrison RA: Molecular mechanisms during sperm capacitation. Hum Fertil (Camb) 2005, 8(4):253-261.

13. Jones R: Plasma membrane structure and remodelling during sperm maturation in the epididymis. J Reprod Fertil Suppl 1998, 53:73-84.

14. Fraser LR: The "switching on" of mammalian spermatozoa: molecular events involved in promotion and regulation of capacitation. Mol Reprod Dev 2010, 77(3):197-208.

15. Gadella BM, Tsai PS, Boerke A, Brewis IA: Sperm head membrane reorganisation during capacitation. Int J Dev Biol 2008, 52(5-6):473-480.

16. Visconti PE, Galantino-Homer H, Moore GD, Bailey JL, Ning X, Fornes M, Kopf GS: The molecular basis of sperm capacitation. J Androl 1998, 19(2):242-248.

17. Visconti PE, Kopf GS: Regulation of protein phosphorylation during sperm capacitation. Biol Reprod 1998, 59(1):1-6.

18. Carrera A, Moos J, Ning XP, Gerton GL, Tesarik J, Kopf GS, Moss SB: Regulation of protein tyrosine phosphorylation in human sperm by a calcium/calmodulin-dependent mechanism: identification of A kinase anchor proteins as major substrates for tyrosine phosphorylation. Dev Biol 1996, 180(1):284-296.

19. Leclerc P, de Lamirande E, Gagnon C: Cyclic adenosine $3^{\prime}, 5^{\prime}$ monophosphate-dependent regulation of protein tyrosine phosphorylation in relation to human sperm capacitation and motility. Biol Reprod 1996, 55(3):684-692.

20. Yanagimachi R: Fertilization in mammals. Tokai J Exp Clin Med 1984, 9(2):81-85. 
21. Ramirez-Torres MA, Carrera A, Zambrana M: [High incidence of hyperestrogenemia and dyslipidemia in a group of infertile men]. Ginecol Obstet Mex 2000, 68:224-229.

22. Padron RS, Mas J, Zamora R, Riverol F, Licea M, Mallea L, Rodriguez J: Lipids and testicular function. Int Urol Nephrol 1989, 21(5):515-519.

23. Schooling CM, Au Yeung SL, Freeman G, Cowling BJ: The effect of statins on testosterone in men and women, a systematic review and meta-analysis of randomized controlled trials. BMC Med 2013, 11:57.

24. Stein EA, Davidson MH, Dobs AS, Schrott H, Dujovne CA, Bays H, Weiss SR, Melino MR, Stepanavage ME, Mitchel YB: Efficacy and safety of simvastatin $80 \mathrm{mg} /$ day in hypercholesterolemic patients. The Expanded Dose Simvastatin U.S. Study Group. Am J Cardiol 1998, 82(3):311-316.

25. Dobs AS, Schrott H, Davidson MH, Bays H, Stein EA, Kush D, Wu M, Mitchel Y, Illingworth RD: Effects of high-dose simvastatin on adrenal and gonadal steroidogenesis in men with hypercholesterolemia. Metabolism 2000, 49(9):1234-1238.

26. Davidson MH, Stein EA, Hunninghake DB, Ose L, Dujovne CA, Insull W Jr, Bertolami M, Weiss SR, Kastelein JJ, Scott RS, Campodónico S, Escobar ID, Schrott HG, Bays H, Stepanavage ME, Wu M, Tate AC, Melino MR, Kush D, Mercuri M, Mitchel YB, Worldwide Expanded Dose Simvastatin Study Group: Lipid-altering efficacy and safety of simvastatin $80 \mathrm{mg} /$ day: worldwide long-term experience in patients with hypercholesterolemia. Nutr Metab Cardiovasc Dis 2000, 10(5):253-262.

27. Azzarito C, Boiardi L, Vergoni W, Zini M, Portioli I: Testicular function in hypercholesterolemic male patients during prolonged simvastatin treatment. Horm Metab Res 1996, 28(4):193-198.

28. Bernini GP, Brogi G, Argenio GF, Moretti A, Salvetti A: Effects of long-term pravastatin treatment on spermatogenesis and on adrenal and testicular steroidogenesis in male hypercholesterolemic patients. J Endocrinol Invest 1998, 21(5):310-317.

29. Azzarito C, Boiardi L, Zini M, Agosti A, Dotti C, Biagi R, Portioli I: Long-term therapy with high-dose simvastatin does not affect adrenocortical and gonadal hormones in hypercholesterolemic patients. Metabolism 1992, 41(2):148-153.

30. Santini SA, Carrozza C, Lulli P, Zuppi C, CarloTonolo G, Musumeci S: Atorvastatin treatment does not affect gonadal and adrenal hormones in type 2 diabetes patients with mild to moderate hypercholesterolemia. J Atheroscler Thromb 2003, 10(3):160-164.

31. Mondul AM, Selvin E, Rohrmann S, Menke A, Feinleib M, Kanarek N, Rifai N, Dobs AS, Platz EA: Association of serum cholesterol and cholesterollowering drug use with serum sex steroid hormones in men in NHANES III. Cancer Causes Control 2010, 21(10):1575-1583.

32. Travia D, Tosi F, Negri C, Faccini G, Moghetti P, Muggeo M: Sustained therapy with 3-hydroxy-3-methylglutaryl-coenzyme-A reductase inhibitors does not impair steroidogenesis by adrenals and gonads. J Clin Endocrinol Metab 1995, 80(3):836-840.

33. Stanworth RD, Kapoor D, Channer KS, Jones TH: Statin therapy is associated with lower total but not bioavailable or free testosterone in men with type 2 diabetes. Diabetes Care 2009, 32(4):541-546.

34. Hyyppa MT, Kronholm E, Virtanen A, Leino A, Jula A: Does simvastatin affect mood and steroid hormone levels in hypercholesterolemic men? A randomized double-blind trial. Psychoneuroendocrinology 2003, 28(2):181-194.

35. Niederberger C: Atorvastatin and male infertility: is there a link? J Androl 2005, 26(1):12

36. WHO: World Health Organization: WHO Laboratory Manual for the Examination of Human Semen and Semen-Cervical Mucus Interaction. 4th edition. Cambridge, UK: Cambridge University Press; 1999

37. Jouannet P, Ducot B, Feneux D, Spira A: Male factors and the likelihood of pregnancy in infertile couples. I. Study of sperm characteristics. Int J Androl 1988, 11(5):379-394.

38. Ratain MJ, Sargent DJ: Optimising the design of phase II oncology trials: the importance of randomisation. Eur J Cancer 2009, 45(2):275-280.

39. BIOFORMA: Exploration de la fonction de reproduction versant masculin, Volume 42. Paris: Formation continue des biologistes; 2009.

40. Grizard G, Ouchchane L, Roddier H, Artonne C, Sion B, Vasson MP, Janny L: In vitro alachlor effects on reactive oxygen species generation, motility patterns and apoptosis markers in human spermatozoa. Reprod Toxicol 2007, 23(1):55-62.

41. Grizard G, Sion B, Jouanel P, Benoit P, Boucher D: Cholesterol, phospholipids and markers of the function of the accessory sex glands in the semen of men with hypercholesterolaemia. Int J Androl 1995, 18(3):151-156.
42. Force A, Grizard G, Giraud MN, Motta C, Sion B, Boucher D: Membrane fluidity and lipid content of human spermatozoa selected by swim-up method. Int J Androl 2001, 24(6):327-334.

43. Rejraji H, Sion B, Prensier G, Carreras M, Motta C, Frenoux JM, Vericel E, Grizard G, Vernet P, Drevet JR: Lipid remodeling of murine epididymosomes and spermatozoa during epididymal maturation. Biol Reprod 2006, 74(6):1104-1113.

44. Flesch FM, Brouwers JF, Nievelstein PF, Verkleij AJ, van Golde LM, Colenbrander B, Gadella BM: Bicarbonate stimulated phospholipid scrambling induces cholesterol redistribution and enables cholesterol depletion in the sperm plasma membrane. J Cell Sci 2001, 114(Pt 19):3543-3555.

45. Gadella BM, Harrison RA: Capacitation induces cyclic adenosine 3',5'monophosphate-dependent, but apoptosis-unrelated, exposure of aminophospholipids at the apical head plasma membrane of boar sperm cells. Biol Reprod 2002, 67(1):340-350.

46. Pons-Rejraji $H$, Bailey JL, Leclerc P: Modulation of bovine sperm signalling pathways: correlation between intracellular parameters and sperm capacitation and acrosome exocytosis. Reprod Fertil Dev 2009, 21(4):511-524.

47. Pons-Rejraji H, Artonne C, Sion B, Brugnon F, Canis M, Janny L, Grizard G: Prostasomes: inhibitors of capacitation and modulators of cellular signalling in human sperm. Int J Androl 2010, 34(6 Pt 1):568-580.

48. Diaz-Fontdevila M, Pena W, Bustos-Obregon E: Experimental hypercholesterolaemia in rabbits. Effect on lipid domains in homologous spermatozoa. Andrologia 1998, 30(1):15-22.

49. Diaz-Fontdevila M, Bustos-Obregon E: Cholesterol and polyunsaturated acid enriched diet: effect on kinetics of the acrosome reaction in rabbit spermatozoa. Mol Reprod Dev 1993, 35(2):176-180.

50. Saez Lancellotti TE, Boarelli PV, Monclus MA, Cabrillana ME, Clementi MA, Espinola LS, Cid Barria JL, Vincenti AE, Santi AG, Fornes MW: Hypercholesterolemia impaired sperm functionality in rabbits. PLOS ONE 2010, 5(10):e13457.

51. Sullivan $R$, Legare $C$, Thabet $M$, Thimon V: Gene expression in the epididymis of normal and vasectomized men: what can we learn about human sperm maturation? J Androl 2012, 32(6):686-697.

52. Robaire B, Hamzeh M: Androgen action in the epididymis. J Androl 2011, 32(6):592-599

53. Green SM, Mostaghel EA, Nelson PS: Androgen action and metabolism in prostate cancer. Mol Cell Endocrinol 2012, 360(1-2):3-13.

54. Castellon EA, Huidobro CC: Androgen regulation of glycosidase secretion in epithelial cell cultures from human epididymis. Hum Reprod 1999, 14(6):1522-1527.

55. Mahmoud AM, Geslevich J, Kint J, Depuydt C, Huysse L, Zalata A, Comhaire FH: Seminal plasma alpha-glucosidase activity and male infertility. Hum Reprod 1998, 13(3):591-595.

56. Muniyan S, Chaturvedi NK, Dwyer JG, Lagrange CA, Chaney WG, Lin MF: Human prostatic Acid phosphatase: structure, function and regulation. Int J Mol Sci 2013, 14(5):10438-10464.

57. Balercia G, Mancini A, Paggi F, Tiano L, Pontecorvi A, Boscaro M, Lenzi A, Littarru GP: Coenzyme Q10 and male infertility. J Endocrinol Invest 2009, 32(7):626-632

58. Littarru GP, Tiano L: Clinical aspects of coenzyme Q10: an update. Nutrition 2010, 26(3):250-254.

59. Purvis K, Tollefsrud A, Rui H, Haug E, Norseth J, Viksmoen L, Ose L, Lund H: Short-term effects of treatment with simvastatin on testicular function in patients with heterozygous familial hypercholesterolaemia. Eur I Clin Pharmacol 1992, 42(1):61-64.

60. Akduman B, Tandberg DJ, O'Donnell Cl, Hughes A, Moyad MA, Crawford ED: Effect of statins on serum prostate-specific antigen levels. Urology 2010, 76(5):1048-1051.

61. Cyrus-David MS, Weinberg A, Thompson T, Kadmon D: The effect of statins on serum prostate specific antigen levels in a cohort of airline pilots: a preliminary report. J Urol 2005, 173(6):1923-1925.

62. Zhuang L, Kim J, Adam RM, Solomon KR, Freeman MR: Cholesterol targeting alters lipid raft composition and cell survival in prostate cancer cells and xenografts. J Clin Invest 2005, 115(4):959-968.

63. Llorente A, van Deurs B, Sandvig K: Cholesterol regulates prostasome release from secretory lysosomes in PC-3 human prostate cancer cells. Eur J Cell Biol 2007, 86(7):405-415.

64. Aberg M, Johnell M, Wickstrom M, Widunder A, Siegbahn A: Simvastatin reduces the production of prothrombotic prostasomes in human prostate cancer cells. Thromb Haemost 2008, 100(4):655-662. 
65. Dobs AS, Miller S, Neri G, Weiss S, Tate AC, Shapiro DR, Musliner TA: Effects of simvastatin and pravastatin on gonadal function in male hypercholesterolemic patients. Metabolism 2000, 49(1):115-121.

66. Dobs AS, Sarma PS, Schteingart D: Long-term endocrine function in hypercholesterolemic patients treated with pravastatin, a new 3-hydroxy-3-methylglutaryl coenzyme A reductase inhibitor. Metabolism 1993, 42(9):1146-1152.

67. Farnsworth WH, Hoeg JM, Maher M, Brittain EH, Sherins RJ, Brewer HB Jr: Testicular function in type II hyperlipoproteinemic patients treated with lovastatin (mevinolin) or neomycin. J Clin Endocrinol Metab 1987, 65(3):546-550.

68. Hall SA, Page ST, Travison TG, Montgomery RB, Link CL, McKinlay JB: Do statins affect androgen levels in men? Results from the Boston area community health survey. Cancer Epidemiol Biomarkers Prev 2007, 16(8):1587-1594.

69. Bohm M, Herrmann W, Wassmann S, Laufs U, Nickenig G: Does statin therapy influence steroid hormone synthesis? Z Kardiol 2004, 93(1):43-48.

70. Jay RH, Sturley RH, Stirling C, McGarrigle HH, Katz M, Reckless JP, Betteridge $D J$ : Effects of pravastatin and cholestyramine on gonadal and adrenal steroid production in familial hypercholesterolaemia. $\mathrm{Br} J \mathrm{Clin}$ Pharmacol 1991, 32(4):417-422.

71. Kocum TH, Ozcan Tl, Gen R, Tekin A, Erol T, Akcay B, Doven O: Does atorvastatin affect androgen levels in men in the era of very-low LDL targeting therapy? Exp Clin Endocrinol Diabetes 2009, 117(2):60-63.

72. Preiss D, Sattar N: Statins and the risk of new-onset diabetes: a review of recent evidence. Curr Opin Lipido/ 2011, 22(6):460-466.

73. Corona G, Boddi V, Balercia G, Rastrelli G, De Vita G, Sforza A, Forti G, Mannucci E, Maggi M: The effect of statin therapy on testosterone levels in subjects consulting for erectile dysfunction. J Sex Med 2010, 7(4 Pt 1):1547-1556.

74. Do C, Huyghe E, Lapeyre-Mestre M, Montastruc JL, Bagheri H: Statins and erectile dysfunction: results of a case/non-case study using the French Pharmacovigilance System Database. Drug Saf 2009, 32(7):591-597.

75. Ding EL, Song Y, Malik VS, Liu S: Sex differences of endogenous sex hormones and risk of type 2 diabetes: a systematic review and meta-analysis. Jama 2006, 295(11):1288-1299.

76. La Vignera S, Condorelli RA, Vicari E, Calogero AE: Statins and erectile dysfunction: a critical summary of current evidence. J Androl 2012, 33(4):552-558.

77. Tobert JA, Bell GD, Birtwell J, James I, Kukovetz WR, Pryor JS, Buntinx A, Holmes IB, Chao YS, Bolognese JA: Cholesterol-lowering effect of mevinolin, an inhibitor of 3-hydroxy-3-methylglutaryl-coenzyme a reductase, in healthy volunteers. J Clin Invest 1982, 69(4):913-919.

doi:10.1186/1477-7827-12-65

Cite this article as: Pons-Rejraji et al.: Evaluation of atorvastatin efficacy and toxicity on spermatozoa, accessory glands and gonadal hormones of healthy men: a pilot prospective clinical trial. Reproductive Biology and Endocrinology 2014 12:65.

\section{Submit your next manuscript to BioMed Central and take full advantage of:}

- Convenient online submission

- Thorough peer review

- No space constraints or color figure charges

- Immediate publication on acceptance

- Inclusion in PubMed, CAS, Scopus and Google Scholar

- Research which is freely available for redistribution 